ORNL/TM-13355

OAK RIDGE

natIONA

LABORATORY
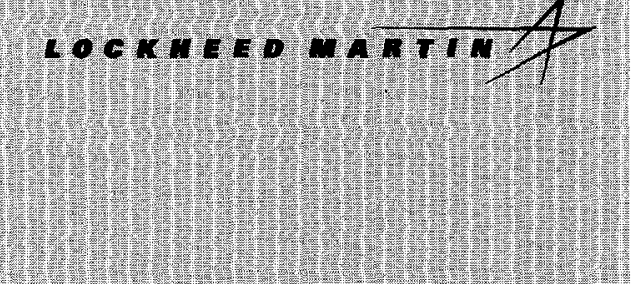

15.

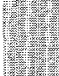

\section{4tist}

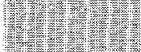

Whes
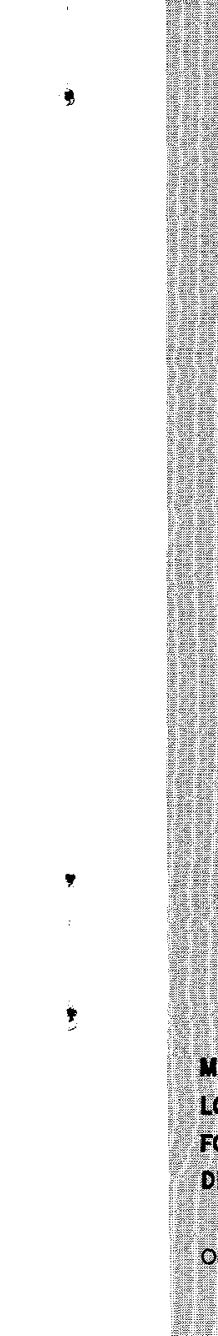

IMWHEED AN OPERATEO BY

LOCKHEED MARTI ENERCY RESEABCH CORPORATION FOR THE UNTED STATES

DEPARTIENT OF ENERGY
RECEIVED

\author{
FEB 161999 \\ OSTI
}

HFIR Vessel Maximum

Permissible Pressures for Operating Period 26 to 50 EFPY (100 MW)

R. D. Cheverton

J. R. Inger

Office of Scientific and Technical Information

P. O. Box 62

Oak Ridge, TN 37831 


\section{DISCLAIMER}

This report was prepared as an account of work sponsored by an agency of the United States Government. Neither the United States Government nor any agency thereof, nor any of their employees, make any warranty, express or implied, or assumes any legal liability or responsibility for the accuracy, completeness, or usefulness of any information, apparatus, product, or process disclosed, or represents that its use would not infringe privately owned rights. Reference herein to any specific commercial product, process, or service by trade name, trademark, manufacturer, or otherwise does not necessarily constitute or imply its endorsement, recommendation, or favoring by the United States Government or any agency thereof. The views and opinions of authors expressed herein do not necessarily state or reflect those of the United States Government or any agency thereof. 


\section{DISCLAIMER}

Portions of this document may be illegible in electronic image products. Images are produced from the best available original document. 


\title{
HFIR VESSEL MAXIMUM PERMISSIBLE PRESSURES FOR OPERATING PERIOD 26 TO 50 EFPY(100 MW)
}

\author{
R. D. Cheverton \\ Delta-21 Resources, Inc.
}

\author{
J. R. Inger \\ Oak Ridge National Laboratory
}

Manuscript completed: September 1997

Manuscript published: January 1999

Prepared by

OAK RIDGE NATIONAL LABORATORY

Oak Ridge, Tennessee 37831-6285 managed by LOCKHEED MARTIN ENERGY RESEARCH INC. for the

U. S. DEPARTMENT OF ENERGY under contract DE-AC05-960R22464 


\section{TABLE OF CONTENTS}

ACKNOWLEDGMENTS

PREFACE

ABSTRACT

1. Introduction $\ldots \ldots \ldots \ldots \ldots \ldots \ldots \ldots \ldots \ldots \ldots \ldots \ldots$

2. Method of Analysis $\ldots \ldots \ldots \ldots \ldots \ldots \ldots \ldots \ldots \ldots \ldots$

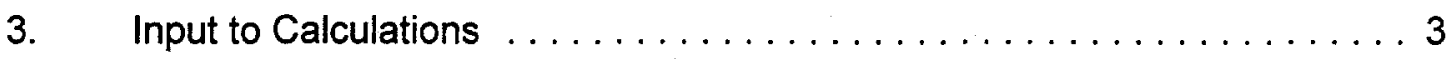

4. Calculations $\ldots \ldots \ldots \ldots \ldots \ldots \ldots \ldots \ldots \ldots \ldots \ldots \ldots$

$4.1 \quad$ Parametric analysis . . . . . . . . . . . . . . . . 4

4.2 Maximum permissible pressure as a function of time for

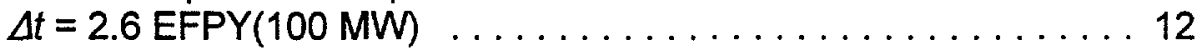

4.3 Sensitivity of $p(t)_{\min }$ to the tolerance on $\Delta t \ldots \ldots \ldots \ldots 17$

4.4 Sensitivity of $p(t)_{\min }$ to flaw growth $\ldots \ldots \ldots \ldots \ldots \ldots \ldots$

4.5 Sensitivity of $p(t)_{\min }$ to characteristics of

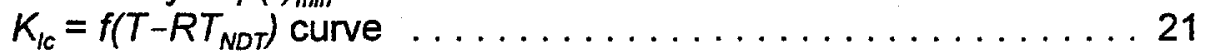

4.6 Minimum value of $p(t)_{\min }$ for $\Delta t=3.0$ and 3.12 EFPY $(100 \mathrm{MW})$

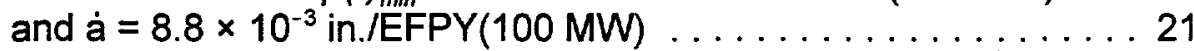

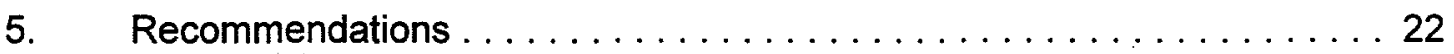

6. Summary and Conclusions $\ldots \ldots \ldots \ldots \ldots \ldots \ldots \ldots \ldots \ldots$

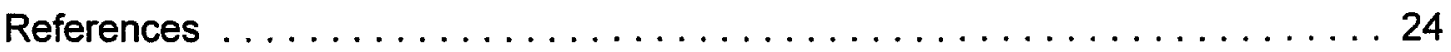

Appendix A: Source of Standard Deviations ( $\sigma$ ) for $R T_{N D T}$

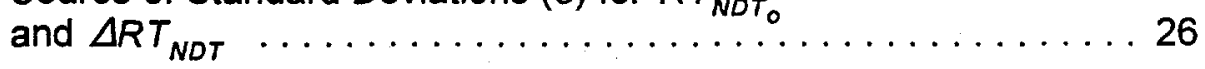

Appendix B: Results of Calculations for the Parametric Study . . . . . . . . . 28

Appendix C: Calculated values of $p(t)$ vs $t$ for $T_{v}(t)=110^{\circ} \mathrm{F}, \Delta t=$

2.6 EFPY $(100 \mathrm{MW}), a=0$

Appendix D: Calculated Values of $p(t)$ vs $t$ for $T_{v}(t)=88^{\circ} \mathrm{F}$,

$\Delta t=2.6 \operatorname{EFPY}(100 \mathrm{MW}), a=0$

Appendix E: Calculated Values of $p(t)$ vs $t$ for $T_{v}(t)=80^{\circ} \mathrm{F}$,

$\Delta t=2.6 \operatorname{EFPY}(100 \mathrm{MW}), a=0$

Appendix F: Comparison of $p(t)$ vs e Obtained Using the ASME

$K_{l c}$ and $K_{\mathbb{R}}$ Curves 


\section{ACKNOWLEDGMENT}

The authors wish to acknowledge contributions made by J. G. Merkle and S. J. Chang (reviewers of the report) and Mary Wells (preparation of the document). 


\section{PREFACE}

This study was completed prior to concluding that (1) hydrostatic proof testing could be substituted for inservice volumetric inspection of some of the primary-system piping welds" and (2) enlargement of the HB-2 and HB-4 beam tubes was feasible." If the hydrostatic proof-testing substitution and/or the design upgrade are in effect during the life-extension period 26 to 50 EFPY $(100 \mathrm{MW})$, hydrostatic proof-test conditions and thus the maximum permissible pressures will be somewhat different than those mentioned in this report. The method of analysis, however, remains valid.

"R. D. Cheverton and J. R. Inger, Determination of the Applicability of Hydrostatic Proof Testing for Demonstrating Integrity of HFIR Primary-System Piping, Vessel, and Related Components, ORNL, RDC/JRI/RRD/LTR-97-2, February 9, 1998.

"R. D. Cheverton and T. L. Dickson, HFIR Vessel Life Extension with Enlarged HB-2 and HB-4 Beam Tubes, ORNL, ORNL/TM-13698, December 1998. 


\section{ABSTRACT}

Extending the life of the HFIR pressure vessel from 26 to 50 EFPY (100 MW) requires an updated calculation of the maximum permissible pressure for a range in vessel operating temperatures $\left(40-120^{\circ} \mathrm{F}\right)$. The maximum permissible pressure is calculated using the equal-potential method, which takes advantage of knowledge gained from periodic hydrostatic proof tests and uses the test conditions (pressure, temperature, and frequency) as input.

The maximum permissible pressure decreases with increasing time between hydro tests but is increased each time a test is conducted. The minimum values that occur just prior to a test either increase or decrease with time, depending on the vessel temperature. The minimum value of these minimums is presently specified as the maximum permissible pressure. For three vessel temperatures of particular interest $(80,88$, and $\left.110^{\circ} \mathrm{F}\right)$ and a nominal time of $3.0 \mathrm{EFPY}(100 \mathrm{MW})$ between hydro tests, these pressures are 677,753 , and 850 psi. For the lowest temperature of interest $\left(40^{\circ} \mathrm{F}\right)$, the maximum permissible pressure is 295 psi. 


\section{HFIR VESSEL MAXIMUM PERMISSIBLE PRESSURES FOR THE OPERATING PERIOD 26 TO 50 EFPY(100 MW)}

\section{Introduction}

Extending the life of the HFIR pressure vessel from $26^{a}$ to $50 \mathrm{EFPY}(100 \mathrm{MW})$ requires the recalculation of the maximum permissible pressures as a function of vessel temperature $\left(T_{v}\right)$. For normal operation, the highest value of $T_{v}$ is $110^{\circ} \mathrm{F}$ (primary-system coolant-inlet temperature equals $120^{\circ} \mathrm{F}$, and pool temperature equals $90^{\circ} \mathrm{F}$ ), and the lowest value is $80^{\circ} \mathrm{F}$ (minimum permissible temperature of coolant in the cooling-tower basin). An intermediate value of particular interest is that used to establish the vessel pressure safety limit. This temperature was specified as the primary-system inletcoolant-temperature trip point for primary-system pressure reduction. This temperature is $88^{\circ} \mathrm{F}^{1}$ There also may be a need to pressurize the primary system when the coolant temperature is below $80^{\circ} \mathrm{F}$, the lowest credible temperature being $40^{\circ} \mathrm{F}$. Thus, maximum permissible pressures are needed for vessel temperatures in the range $40-120^{\circ} \mathrm{F}$.

There are two basic methods for calculating the maximum permissible pressure: ASME Code, ${ }^{2}$ which uses rather large safety factors to account for uncertainties and (2) the equal-potential method, which takes advantage of knowledge gained from periodic hydrostatic proof tests. This latter method is the one used for calculating the hydro-test conditions ${ }^{3}$ and is also the method used in this report for calculating the recommended maximum permissible pressures. It results in higher pressures than obtained with the ASME Code because a successful hydro test reduces the uncertainties.

In previous calculations of pressures for the low end of the temperature range $\left(40-80^{\circ} \mathrm{F}\right)$, the ASME Code approach was used, ${ }^{3,4,5}$ and the relatively low pressures did not constitute excessive restrictions. Even so, it is prudent to achieve as much operational flexibility as is reasonable, and this can be accomplished by using the method that results in the highest permissible pressure.

The presently specified maximum permissible life for the HFIR pressure vessel is 26 EFPY(100 MW), which will be achieved in $~ 2005$. 


\subsection{Method of Analysis}

As discussed in Ref. 6 , the condition that must be satisfied in the equal-potential method is

$$
\frac{K_{\lambda}(t)}{K_{l c}(t)} \leq \frac{K_{(}(H T)}{K_{l c}(H T)},
$$

$$
\begin{aligned}
& \text { where } K_{l}(t) \quad=\quad \text { stress intensity factor at time } t \text { during normal operation } \\
& K_{l}(H T)=\text { stress intensity factor for hydro-test conditions } \\
& K_{l c}(t)=\text { fracture toughness of material at time } t \text { during "normal" } \\
& \text { operation } \\
& K_{l c}(H T)=\text { fracture toughness of material for hydro-test temperature and } \\
& \text { time. } \\
& K_{p} / K_{1 c} \quad=\quad \text { potential for propagation of flaw (vessel failure) }
\end{aligned}
$$

Substituting expressions for $K_{k}$

$$
\begin{aligned}
p(t) & =p(H T) \frac{K_{l c}(t)}{K_{l c}(H T)}\left(1+\frac{\Delta a}{a}\right)^{-0.5}+S\left[\frac{K_{l c}(t)}{K_{l c}(H T)}\left(1+\frac{\Delta a}{a}\right)^{-0.5}-1\right], \\
& =[p(H T)+S]\left(1+\frac{\Delta a}{a}\right)^{-0.5} \cdot \frac{K_{l c}(t)}{K_{l c}(H T)}-S
\end{aligned}
$$

where $\Delta a=\dot{a} \cdot \Delta t$

$$
\begin{array}{lll} 
& = & \text { flaw growth during } \Delta t \\
a & = & \text { flaw depth at time of "initial" hydro test" } \\
a & = & \text { rate of flaw growth } \\
\Delta t & = & \text { time between hydro tests } \\
p(t) & = & \text { maximum permissible pressure at time } t \\
p(H T) & = & \text { hydro-test pressure }
\end{array}
$$

${ }^{b}$ Because $\Delta a$ is quite small compared to $\underline{a}$, and because $p(t)$ is insensitive to the value of $\underline{a}^{3}$ the same value of $\underline{a}$ is used for all pairs of $t$ and $t(H T)$. 


$$
\begin{array}{rll}
S & =\frac{c_{r} \sigma_{r}}{c_{m} s_{m}+c_{b} s_{b}} \\
c & =\text { crack characterization factor } \\
s & =\quad / p \\
\sigma & =\text { far-field stress } \\
m, b, r & =\text { membrane, bending, residual }
\end{array}
$$

Use of the equality sign in Eq. (2) is justified by including appropriate uncertainty factors for specific parameters.

The expressions for $K_{l c}$ are

$$
\begin{gathered}
K_{1 c}(t)=A+B \exp [C \cdot E(t)], \\
K_{l c}(H T)=A+B \exp [C \cdot E(H T)],
\end{gathered}
$$

where

$$
A, B, C=\text { constants }
$$

$$
\begin{aligned}
& E(t)=T_{v}(t)-R T_{N D T}(t)=T_{v}(t)-R T_{N D T_{0}}-e \cdot \Delta N \dot{D} T T \cdot t \\
& E(H T)=T_{v}(H T)-R T_{N D T}(H T)=T_{v}(H T)-R T_{N D T_{0}}-e \cdot \Delta N D T T \cdot t(H T) \\
& t(H T) \leq t \leq t(H T)+\Delta t \\
& T_{v}(H T)=\text { temperature of vessel during hydro test } \\
& R T_{N D T}=\quad \text { nil-ductility reference temperature } \\
& R T_{N D T_{0}}=\quad \text { initial value of } R T_{N D T} \\
& \triangle N D T T=\quad \text { rate of increase of nil-ductility transition temperature }
\end{aligned}
$$




$$
\begin{array}{lll}
e & = & \text { uncertainty factor applied to } \triangle N D T T \\
t & = & \text { reactor operating time } \\
t(H T) & = & \text { time of hydro test } \\
\Delta t & = & \text { time between hydro tests }
\end{array}
$$

The flaw specified by the ASME Code ${ }^{2}$ is a semi-elliptical surface crack normal to the surface and to the principle stresses. It has a surface-length to depth ratio of 6 and a depth of $1.0 \mathrm{in}$. The critical location (maximum value of $K / K_{1 c}$ ) of the flaw is at the inner surface of the vessel in the nozzle weld directly above the HB-3 nozzle, and it is oriented axially. ${ }^{7}$

The above method of analysis is based on plain-strain linear elastic fracture mechanics (LEFM), the applicability of which is limited by $T-R T_{N D T}$ and dimensions of the "specimen" relative to the size of the plastic zone at the tip of the flaw. The dimensions of the vessel wall and of the hypothetical flaws are not limiting for the HFIR analysis, and as indicated by the results of the analyses, values of $T-R T_{N D T}$ are well below a marginally limiting value of $50^{\circ} \mathrm{F}$.

\section{Input to Calculations}

With a few exceptions, input for the calculations was taken from Table 5.1 of Ref. 3 and is included here in Table 1. The exceptions pertain to values of $p(H T), T_{v}(t), t(H T), \Delta t$, $e, R T_{N D T_{0}}$, and $a$. The value of the hydro-test pressure $[p(H T)]$ included in Table 1 is the value proposed for operation beyond 26 EFPY $(100 \mathrm{MW}) .^{8}$

As indicated in the "Introduction," several specific values of the vessel temperature $\left[T_{v}(t)\right]$ are considered. For normal steady-state operation, the temperature of the primarysystem coolant adjacent to the vessel wall is $120^{\circ} \mathrm{F}$, the temperature of the pool water is $90^{\circ} \mathrm{F}$, and the fluid-film heat transfer coefficients are nearly equal. Thus, the temperature at the tip of the assumed 1.0-in.-deep, inner-surface flaw is $\sim 110^{\circ} \mathrm{F}$. 
Table 1. Input data for calculation of $p(t)$

\begin{tabular}{|c|c|}
\hline Parameter & Value \\
\hline$K_{I c}$ vs $T-R T_{N D T}$ & ASME $K_{t c}$ (Ref. 9) \\
\hline$A, \mathrm{ksi} \sqrt{\text { in. }}$ & 33.2 \\
\hline$B, \mathrm{ksi} \sqrt{\text { in. }}$ & 20.73 \\
\hline$C,{ }^{\circ} \mathrm{F}^{-1}$ & 0.0200 \\
\hline$a_{1}$ in. & 1.0 \\
\hline$\dot{a}$, in./EFPY $(100 \mathrm{MW})$ & $0.0,8.8 \times 10^{-3}$ (Ref. 8 ) \\
\hline$c_{b}$ & 0.741 (Ref. 4) \\
\hline$c_{m}$ & 1.146 (Ref. 4) \\
\hline$c_{r}$ & 0.860 (Ref. 4) \\
\hline$s_{b}$ & 4.24 (Ref. 4 ) \\
\hline$s_{m}$ & 16.8 (Ref. 4) \\
\hline$\sigma_{r}, \mathrm{ksi}$ & 8.5 (Ref. 4 ) \\
\hline$p(H T), \mathrm{ksi}$ & 0.850 (Ref. 4 ) \\
\hline$R T_{\text {NDTO }},{ }^{\circ} \mathrm{F}$ & $10 \pm 34$ \\
\hline$\triangle N D^{\prime} T T,{ }^{\circ} \mathrm{F} / \mathrm{EFPY}(100 \mathrm{MW})(\mathrm{a}=1.0 \mathrm{in})$. & 2.44 (Refs. 3,8 ) \\
\hline$e$ & $0.5-1.5$ \\
\hline$T_{v}(H T),{ }^{\circ} \mathrm{F}$ & 85 \\
\hline$T_{v}(t),{ }^{\circ} \mathrm{F}$ & $40-120$ \\
\hline$t(H T)$, EFPY $(100 \mathrm{MW})$ & $26+(n-1) \Delta t, n=1,2, \cdots 9$ \\
\hline$\Delta t, \operatorname{EFPY}(100 \mathrm{MW})$ & $2.6 \begin{array}{c}+0.12 \\
-0.00\end{array}, 3.0 \quad \begin{array}{r}+0.12 \\
-0.00\end{array}$ \\
\hline
\end{tabular}

The next highest vessel temperature of particular concern is the minimum value corresponding to the primary-system coolant inlet-temperature trip point for system depressurization. This minimum value is $88^{\circ} \mathrm{F}$, conservatively neglecting the difference in temperature between the primary-system coolant and that in the pool. 
The lowest vessel temperature for "normal" operation is conservatively assumed to be equal to the minimum temperature of the coolant in the basin of the cooling tower. This limiting temperature has not yet been specified for reactor operation beyond 26 EFPY $(100 \mathrm{MW})$ but is expected to be close to $80^{\circ} \mathrm{F}$. Because of thermal inertia in the primary and secondary systems, it is very unlikely that the vessel temperature would be at the basin value. If the calculated maximum permissible pressure corresponding to the basin temperature is too low, a more rigorous evaluation of vessel temperature may be required.

For low-pressure/low-temperature operation, the range of temperatures of interest is 40 to $80^{\circ} \mathrm{F}$.

The minimum value of the maximum permissible pressure is sensitive to the value of $t(H T)$, and depending on the vessel temperature, the proper value to use could be either early or late in the vessel life-extension period. Thus, values of $p(t)$ were calculated as a function of time to establish the trend, in which case several values of $t(H T)$ were used. The smallest value was $26 \mathrm{EFPY}(100 \mathrm{MW})$; the largest value was $50-\Delta t$, intermediate values were $26+(n-1) \Delta t$, where $n$ is the sequence number of the test.

Beginning in 1989, at the time of HFIR restart, the specified time between hydro tests was 1.0 EFPY(85MW), but recently a value of $3.0 \mathrm{EFPY}(85 \mathrm{MW})$ [2.6 EFPY(100 MW)] was proposed ${ }^{10}$ and accepted for operation between 19.4 and 26 EFPY(100 MW). A value of 3.0 EFPY ( $100 \mathrm{MW}$ ) is tentatively proposed for the life-extension period 26 to $50 \operatorname{EFPY}(100 \mathrm{MW}){ }^{8}$

There are tolerances on $t(H T)$ and $\Delta t$ to provide reasonable flexibility in scheduling. Presently specified tolerances on $\Delta t$ are ${ }_{-0.00}^{+0.12} \operatorname{EFPY}(100 \mathrm{MW})$. A reasonable tolerance for the initial value of $t(H T)[\sim 26 \mathrm{EFPY}(100 \mathrm{MW})]$ cannot be specified at this time and thus has not been included in this study.

The value of $e$, the uncertainty factor applied to the damage rate $\left(\triangle N D^{\prime} T T\right)$, that results in the lowest values of $p(t)$ is not the same for all cases (vessel temperatures), as illustrated below with reference to Eqs. (2)-(8): 
Case 1: $\quad T_{v}(t)>T_{v}(H T)$

For $e=0, K_{l c}(t)>K_{l c}(H T)$

$\therefore p(t)>p(H T)$

For $e=\infty, K_{1 c}(t)=K_{1 c}(H T)$

$\therefore p(t)=p(H T)$

Thus, $e$ (max) tends to result in the lowest value of $p(t)$.

Case 2: $T_{v}(t)<T_{v}(H T)$

For $e=0, K_{l c}(t)<K_{l c}(H T)$

$\therefore p(t)<p(H T)$

For $e=\infty, K_{l c}(t)=K_{l c}(H T)$

$\therefore p(t)=p(H T)$

Thus, $e(\min )$ tends to result in the lowest value of $p(t)$.

Case 3: $T_{v}(t)=T_{v}(H T)$

For $e=0, K_{l c}(t)=K_{l c}(H T)$

$\therefore p(t)=p(H T)$

For $e=\infty, K_{l c}(t)=K_{1 c}(H T)$

$\therefore p(t)=p(H T)$

For Case 3, there may be a value of $e$ within specified extremes that results in $p(t)<$ $p(H T)$. Thus, several values of e must be considered. A reasonable range is 0.5 to $1.5,^{3}$ although this range could shrink as more surveillance data become available.

The uncertainty of $\pm 34^{\circ} \mathrm{F}$ included in Table 1 for $R T_{N D T_{0}}$ is a two-standard deviation (20) value that was recommended by the Nuclear Regulatory Commission (NRC) for pressure vessel steels (see Appendix $A$ ) and was used in the evaluation of the HFIR vessel life extension. ${ }^{8}$ With reference to Eqs. (5)-(9), increasing $R T_{N D T_{0}}$ tends to either increase or decrease $K_{l c}(t) / K_{l c}(H T)$ depending on the relative values of $T_{v}(t)$ and $T_{v}(H T)$, but in either case driving it to unity ( $K_{I c}$ approaches $A$ ). Thus, several values of $R T_{N D T}$ 
and $e$ within the specified limits must be considered in a parametric evaluation to find the "optimum" values.

The value of $\triangle N D T T$ included in Table 1 was obtained from a transposition of surveillance data to the location of the flaw tip. This was done in Ref. 4 and was updated in Ref. 3, both times using the neutron flux above $1.0 \mathrm{MeV}$ in the transposition process. More recently, ${ }^{8}$ the process was repeated, accounting for the effect of gammas on the distribution of damage. The value of $\triangle N D T T$ for the particular location was the same as obtained in Ref. 3 and is the value given in Table 1 of this report. It is expected that a more rigorous evaluation of the gamma effect will be made in the near future, but it is believed that the range of e values included in the present study is sufficient to cover the present uncertainty. ${ }^{7}$

The value of $a=8.8 \times 10^{-3}$ in./EFPY $(100 \mathrm{MW})$ was taken from Ref. 8 . It is ten times the value calculated using the method included in the ASME Code ${ }^{9}$ and is considered to be $a+2 \sigma$ value. The effect of including flaw growth is quite small, ${ }^{8}$ and for that reason it was excluded from many of the earlier calculations and also from some of the calculations in this report, in which case $\dot{a}=0$.

\subsection{Calculations}

\subsection{Parametric analysis}

The purpose of the parametric aspect of the analysis was to determine the values of $t$, $e$, and $R T_{N D T_{0}}$ that result in the minimum value of the maximum permissible pressure. The parametric analysis was performed using at least three values of $e(0.5,1.0$, and 1.5), three values of $R T_{N D T_{0}}\left(-24,10\right.$, and $\left.44^{\circ} \mathrm{F}\right), \dot{a}=0, \Delta \mathrm{t}=2.6 \mathrm{EFPY}(100 \mathrm{MW})$, and two pairs of $t(H T)$ and $t[26,28.6$, and $47.4,50$ EFPY $(100 \mathrm{MW})]$.

The independent variable in the analysis is $T_{v}(t)$, and, as indicated earlier, the range of interest is $40-120^{\circ} \mathrm{F}$. Parameters in Eqs. (2)-(8) that have values common to all calculations are $\dot{a}, A, B, C, \triangle N D^{\circ} T T$, the stress-related terms $\left(c, s, \sigma_{r}\right), p(H T)$, and $T_{v}(H T)$. By introducing the values of these parameters, Eqs. (2)-(8) become, in the order of the calculational process, 


$$
\begin{aligned}
t & =t(H T)+\Delta t \\
E(t) & =T_{v}(t)-R T_{N D T_{0}}-2.44 e \cdot t \\
E(H T) & =85-R T_{N D T_{0}}-2.44 e \cdot t(H T) \\
K_{I c}(t) & =33.2+20.73 \exp [0.02 E(t)] \\
K_{l c}(H T) & =33.2+20.73 \exp [0.02 E(H T)] \\
S & =\frac{0.860 \times 8.5 \times 10^{3}}{1.146 \times 16.8+0.741 \times 4.24}=326 \mathrm{psi} \\
\Delta a & =0.0 \quad \frac{K_{l c}(t)}{K_{l c}(H T)}+326\left[\frac{K_{/ c}(t)}{K_{l c}(H T)}-1\right] \\
p(t) & =850
\end{aligned}
$$

All of the values of $p(t)$ calculated for $\Delta t=2.6 \mathrm{EFPY}(100 \mathrm{MW})$ to determine the minimum value for each of the vessel temperatures considered in the range 40 to $120^{\circ} \mathrm{F}$ are included in Appendix $B$, and the minimum value for each temperature is included in Table 2, which also includes the corresponding "optimum" values of $t, t(H T), e$, and $R T_{N D T_{0}}$. The time $t$ in Table 2 is the time for which the minimum value of $p(t)$ was calculated, and $t(H T)$ is the time of the preceding hydro test.

The above minimum values of $p(t)$, which constitute the maximum permissible pressures, if only one value is specified for each temperature for the duration of the lifeextension period, are plotted in Fig. 1 as a function of vessel temperature. 
Table 2. Calculated minimum values of $p(t)$ vs vessel temperature, and the corresponding "optimum" values of $t, t(H T), e$, and $R T_{N D T_{o}}$; $a=0, \Delta t=2.6$ EFPY $(100 \mathrm{MW})$

\begin{tabular}{|c|c|c|c|c|c|}
\hline \multirow{2}{*}{$\begin{array}{c}T_{v}(t) \\
{ }^{\circ} \mathrm{F}\end{array}$} & $t$ & $t(H T)$ & \multirow{2}{*}{$e$} & \multirow{2}{*}{$R T_{N D T_{0}}$} & \multirow{2}{*}{$\begin{array}{c}p(t)_{\min } \\
\text { psi }\end{array}$} \\
\hline & \multicolumn{2}{|c|}{ EFPY $(100 \mathrm{MW})$} & & & \\
\hline 40 & 28.6 & 26 & 0.5 & -24 & 308 \\
\hline 50 & 28.6 & 26 & 0.5 & -24 & 382 \\
\hline 60 & 28.6 & 26 & 0.5 & -24 & 472 \\
\hline 70 & 28.6 & 26 & 0.5 & -24 & 583 \\
\hline 80 & 28.6 & 26 & 1.0 & -24 & 705 \\
\hline 85 & 28.6 & 26 & 1.4 & -24 & 758 \\
\hline 88 & 28.6 & 26 & 1.5 & -24 & 785 \\
\hline 90 & 28.6 & 26 & 1.5 & -24 & 804 \\
\hline 95 & 50 & 47.4 & 1.5 & 44 & 850 \\
\hline 100 & 50 & 47.4 & 1.5 & 44 & 856 \\
\hline 110 & 50 & 47.4 & 1.5 & 44 & 868 \\
\hline 120 & 50 & 47.4 & 1.5 & 44 & 883 \\
\hline
\end{tabular}


ORNLTM-13355

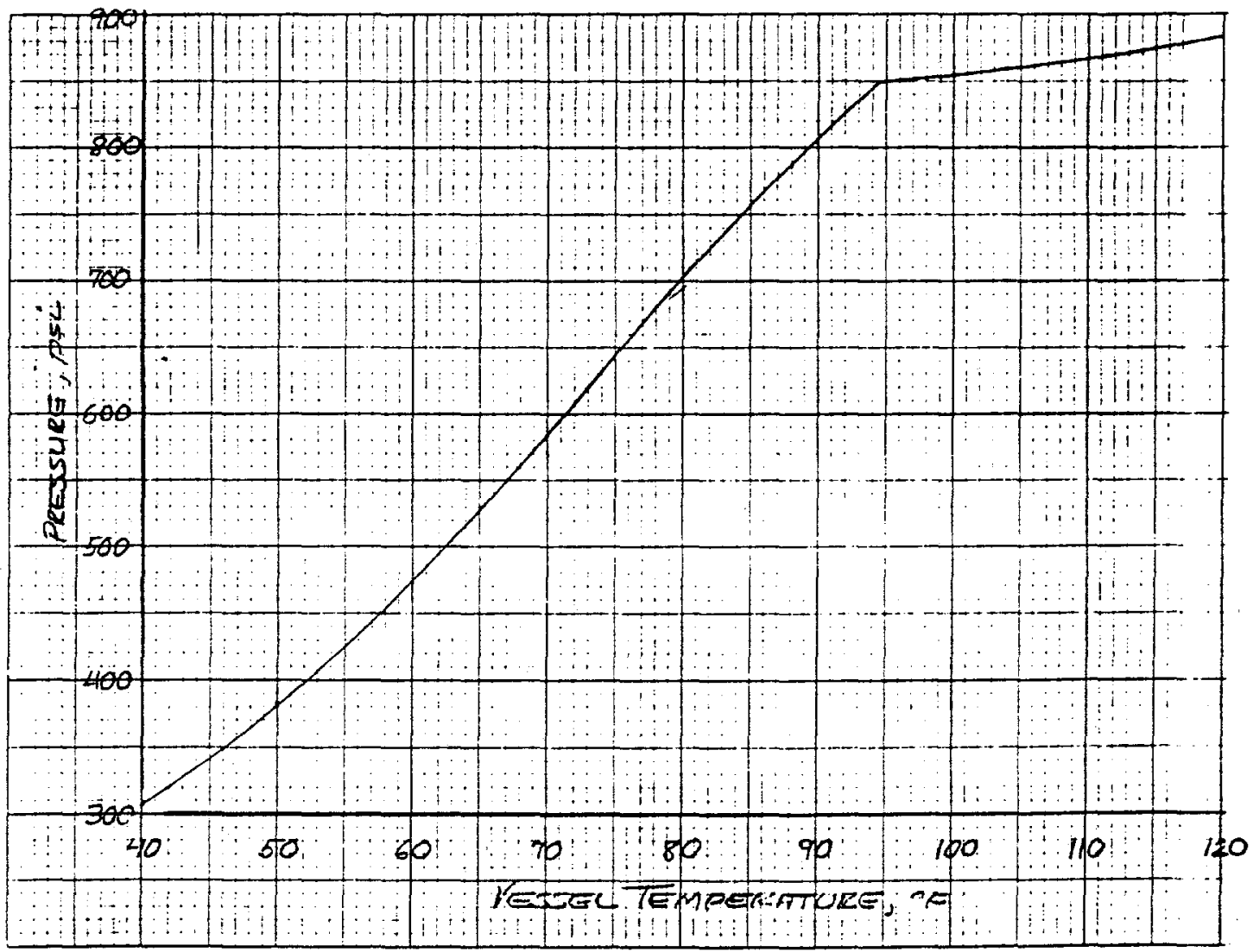

Fig. 1. Maximum permissible pressure [minimum value of $p(t)_{\min }$ ] vs. temperature for life-extension period 26-50 EFPY(100 MW), $p(H T)=850$ psi, $T_{v}(H T)=85^{\circ} \mathrm{F}, \Delta t=2.60 \mathrm{EFPY}(100 \mathrm{MW}), a=0$. 
The discontinuity in Fig. 1 indicates a step change in one or more of the parameters in the equations, and, as indicated in Table 2, there is a step change in $t$ [28.6 to 50 EFPY(100MW)] and $R T_{N D T_{0}}\left(-24\right.$ to $\left.44^{\circ} \mathrm{F}\right)$ between $T_{v}(t)=90$ and $95^{\circ} \mathrm{F}$, consistent with the value of $T_{\mathrm{v}}(t)$ at which the discontinuity occurs. Also, the results in Appendix $\mathrm{B}$ indicate that at $T_{v}(t) \approx 95^{\circ} \mathrm{F}$ the minimum value of $p(t)$ is nearly independent of the values of $t$ and $R T_{N D T_{0}}$ and is approximately equal to $850 \mathrm{psi}=p(H T)$. For $p(t)=p(H T)$ and $a$ $=0$, Eqs. (5) and (6) must be equal, and thus Eqs. (7) and (8) must also be equal. Setting Eqs. (7) and (8) equal to each other and solving for $T_{v}(t)$ results in

$$
\begin{aligned}
T_{v}(t) & =T_{v}(H T)-R T_{N D T_{0}}-e \cdot \Delta N \dot{D} T T(t-\Delta t)+R T_{N D T_{0}}-e \cdot \Delta N \dot{D} T T t \\
& =T_{v}(H T)+e \cdot \Delta N \dot{D} T T \cdot \Delta t
\end{aligned}
$$

As indicated by Eq. (10) and also by the data in Appendix B, the value of $T_{v}(t)$ corresponding to $p(t)=p(H T)$ is independent of $t$ and $R T_{N D T_{0}}$.

Consistent with Tables 1 and 2, Eq. (10) yields

$$
T_{v}(t)(\dot{a}=0, \Delta t=2.6 \operatorname{EFPY}(100 \mathrm{MW}))=85+1.5 \times 2.44 \times 2.6=94.5^{\circ} \mathrm{F}
$$

The reduction in $d p(t) / d T_{v}(t)$ at $T_{v}(t)=94.5^{\circ} \mathrm{F}$ is the result of the step increase in $t$ and $R T_{N D T_{0}}$. Increasing these two parameters decreases $T_{v}(t)-R T_{N D T}$, in which case $K_{l c}(t) / K_{l c}(H T)$ approaches unity asymptotically. Thus, $d p(t) / d\left[T_{v}(t)\right]$ approaches zero.

\subsection{Maximum permissible pressure as a function of time for $\Delta t=2.6 \mathrm{EFPY}(100$ MW)}

Based on the above discussion, for $T_{v}(t)(a=0, \Delta t=2.6)=94.5^{\circ} \mathrm{F}$, the maximum permissible pressure is independent of time and is equal to $850 \mathrm{psi}$, the hydro-test pressure. Thus, for $T_{v}(t)>94.5^{\circ} \mathrm{F}$, the maximum permissible pressure is greater than $850 \mathrm{psi}$ but decreases with time, becoming asymptotic to $850 \mathrm{psi}$. For $T_{v}(t)<94.5^{\circ} \mathrm{F}$, the maximum permissible pressure is less than 850 psi but increases with time, also 
becoming asymptotic to $850 \mathrm{psi}$. Thus, for $T_{v}(t)>94.5^{\circ} \mathrm{F}$, the minimum value of the maximum permissible pressure occurs at the end of the life-extension period, and it occurs at the "beginning" [28.6 EFPY $(100 \mathrm{MW})]$ of the life-extension period for $T_{v}(t)$ $<94.5^{\circ} \mathrm{F}$.

The above trends are indicated in Table 2 and are illustrated graphically in Figs. 2, 3, and 4, which are plots of $p(t)$ vs $t$ for $T_{v}(t)=110,88$ and $80^{\circ} \mathrm{F}, a=0$ and $\Delta t=2.6$ EFPY (100 MW). (Tabulated data for these figures are included in Appendices $C, D$, and $E$.)

The solid line in Figs. 2, 3, and 4 represents the maximum permissible pressure, if only one hydro test were conducted for the life-extension period (no beneficial effect of hydro testing), and the minimum values occur at the end of the life extension period. When hydro tests are conducted periodically, $p(t)$ is characterized by a gradual decrease during the time between tests, but immediately following a hydro test, $p(t)$ is restored to nearly the maximum value corresponding to the previous test because of the step decrease in $K_{l c}(H T)$ in Eq. (2) each time a test is conducted. Thus, at the time of each hydro test there are both minimum (pretest) and maximum (post test) values of $p(t)$. As indicated above and in the figures, the minimum value of $p(t), p(t)_{\text {min }}$ either increases or decreases with time, depending on the value of $T_{v}(t)$, becoming asymptotic to $p(H T)$. Thus, the minimum value of $p(t)_{\min }$ occurs either at the beginning or end of the life-extension period, as indicated above. These are the values that are plotted in Fig. 1.

The calculations pertaining to Figs. 2, 3, and 4 were made using Eqs. (2)-(8) with values of $e$ and $R T_{N D T_{o}}$ that resulted in the minimum value of $p(t)_{\min }$. For times substantially different than those corresponding to the minimum value of $p(t)_{\min }$ the values of $p(t)_{\min }$ may not be as low as those obtained with other values of $e$ and $R T_{N D T_{0}}$. However, the lowest values achievable are not less than the minimum value of $p(t)_{\min }$ in the figures. These trends are indicated by the data in Appendix $B$. 


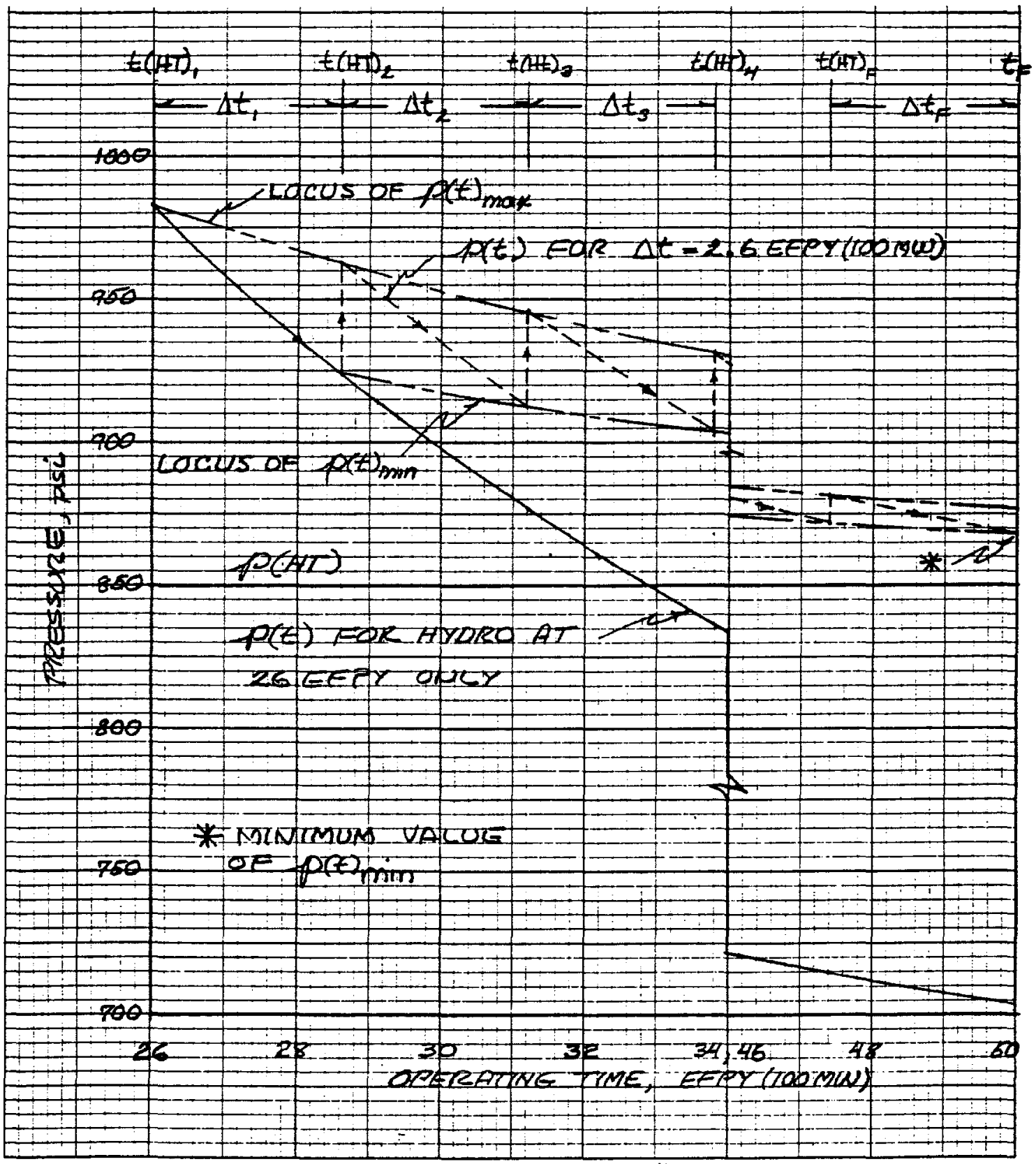

Fig. 2. Maximum permissible pressure vs time, with and without beneficial effect of hydro testing, for $T_{v}(t)=110^{\circ} \mathrm{F}, p(H T)=850 \mathrm{psi}, T_{v}(H T)=85^{\circ} \mathrm{F}, \Delta t=$ 2.6 EFPY $(100 \mathrm{MW}), t(H T)($ initial $)=26 \operatorname{EFPY}(100 \mathrm{MW}),\left(e=1.5, R T_{N D T_{o}}=44^{\circ} \mathrm{F}\right)$. 


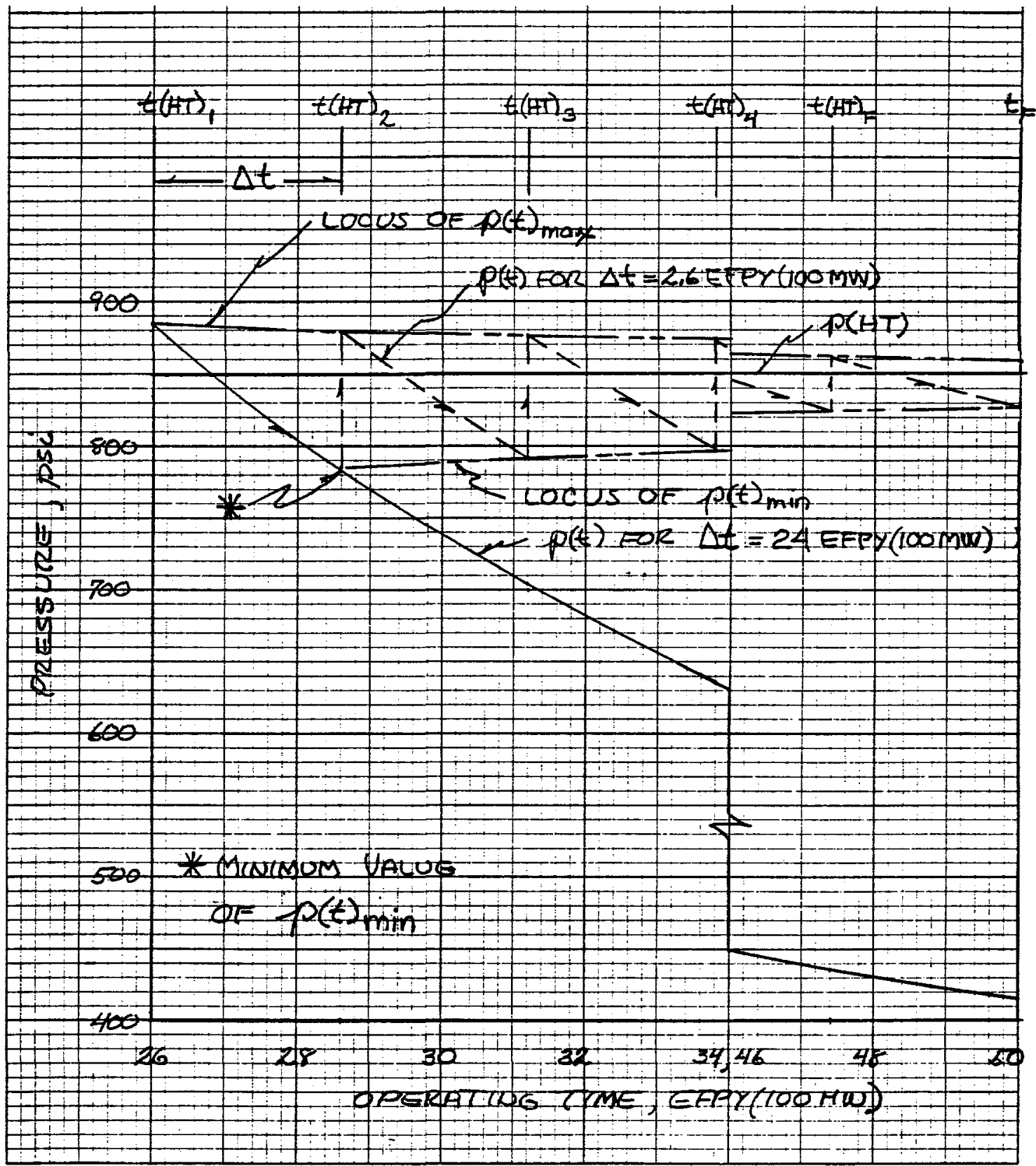

Fig. 3. Maximum permissible pressure vs time, with and without beneficial effect of hydro testing, for $T_{v}(t)=88^{\circ} \mathrm{F}, \mathrm{p}(\mathrm{HT})=850 \mathrm{psi}, \mathrm{T}_{\mathrm{v}}(\mathrm{HT})=85^{\circ} \mathrm{F}, \Delta t=$ 2.6 EFPY $(100 \mathrm{MW}), t(H T)$ (initial) $=26 \operatorname{EFPY}(100 \mathrm{MW}),\left(e=1.5, R T_{N D T_{o}}=-24^{\circ} \mathrm{F}\right)$. 


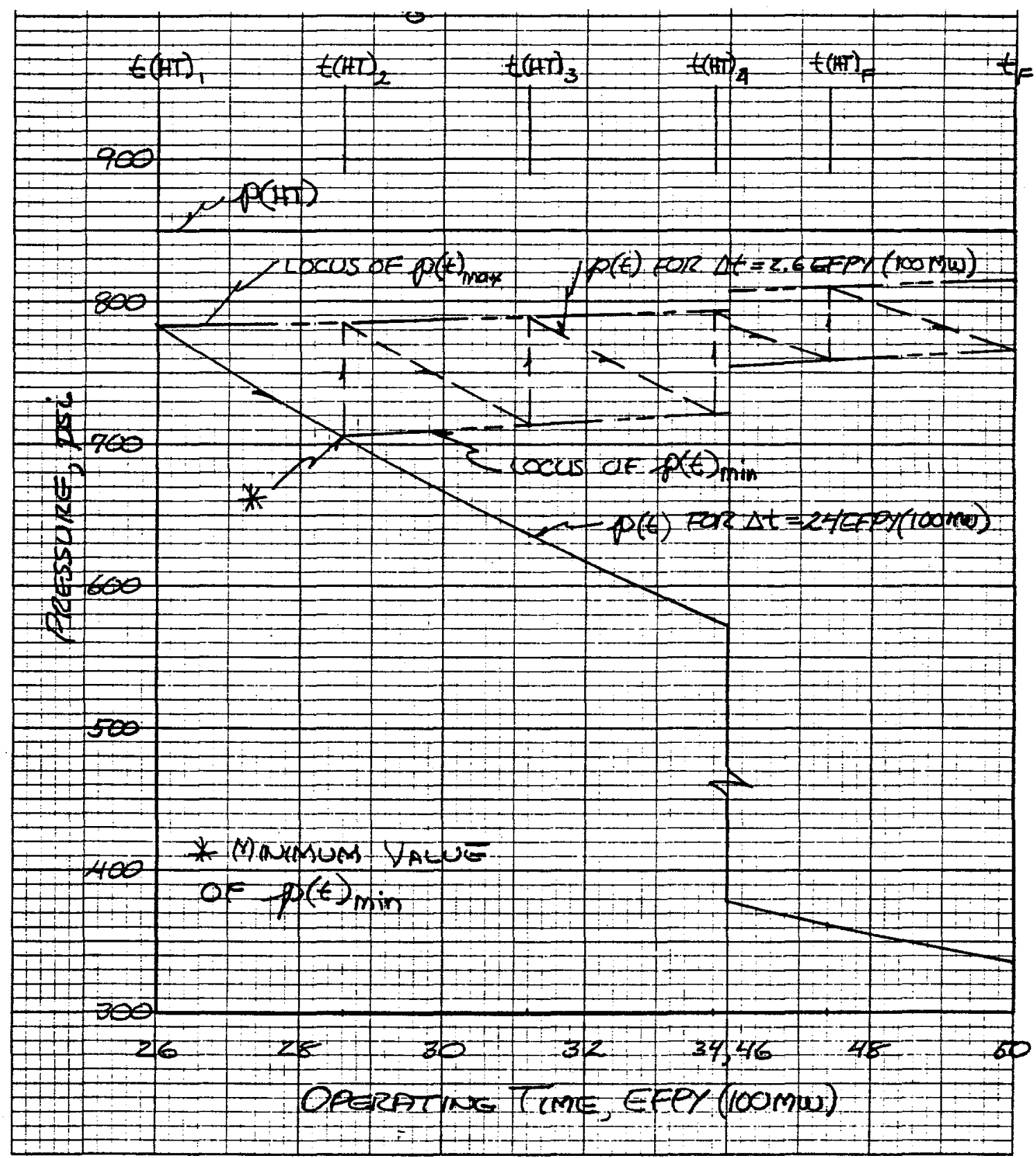

Fig. 4. Maximum permissible pressure vs time, with and without beneficial effect of hydrotesting, for $T_{v}(t)=80^{\circ} \mathrm{F}, \mathrm{p}(H T)=850 \mathrm{psi}, \mathrm{T}_{v}(H T)=85^{\circ} \mathrm{F}, \Delta t=2.6$ EFPY $(100 \mathrm{MW}), t(\mathrm{HT})$ (initial) $=26 \mathrm{EFPY}(100 \mathrm{MW}),\left(e=1.0, R T_{N D T_{o}}=-24^{\circ} \mathrm{F}\right)$. 
As indicated by Figs. 2, 3, and 4, and by the data in Appendices $C, D$, and $E$, the minimum values of $p(t)_{\min }$ for $T_{v}(t)=110,88$, and $80^{\circ} \mathrm{F}$ are 868,785 , and 705 psi. If only one value of the maximum permissible pressure is to be specified for each of these temperatures for a specified period of time, such as the entire life-extension period, these values must be specified. However, if values are specified for successive time periods, higher values can be specified for some of those periods. Also, as more surveillance data become available, it may be possible to reduce the extremes of $e$, and that also will increase $p(t)_{\text {min }}$.

\subsection{Sensitivity of $p(t)_{\min }$ to the tolerance on $\Delta t$}

As indicated in Table 1, the presently specified tolerance on $\Delta t$ is ${ }_{-0.00}^{+0.12}$ EFPY(100 MW). To determine the effect of this tolerance, minimum values of $p(t)_{\min }$ were calculated for $a$ $=0$ and $\Delta t=2.60+0.12=2.72$ EFPY $(100 \mathrm{MW})$ to compare with the values in Table 2 . The comparison is made in Table 3, which indicates that the decrease in the minimum value of $p(t)_{\min }$ that results from adding the tolerance to $\Delta t$ increases from $1 \mathrm{psi}$ for $T_{v}(t)=$ $40^{\circ} \mathrm{F}$ to 4 psi for $T_{v}(t)=90^{\circ} \mathrm{F}$. For $T_{v}(t)>95^{\circ} \mathrm{F}$, the decrease is less than 1 psi. Thus, the effect is very small.

The temperature corresponding to $p(t)=p(H T)$ is obtained from Eq. (10) and for $\Delta t=$ 2.72 EFPY(100 MW) is

$$
T_{v}(t)[p(t)=p(H T)]=85+1.5 \times 2.44 \times 2.72=95.0^{\circ} \mathrm{F}
$$


Table 3. Calculated minimum values of $p(t)_{\min }$ vs vessel temperature for $\Delta t=2.60$, $2.72,3.00$, and $3.12 \mathrm{EFPY}(100 \mathrm{MW})$ with $\dot{a}=0$ or $\dot{a}=8.8 \times 10^{-3}$ in./EFPY $(100 \mathrm{MW})^{\mathrm{a}}$

\begin{tabular}{|c|c|c|c|c|c|}
\hline \multirow{2}{*}{$\begin{array}{l}T_{v}(t) \\
{ }^{\circ} \mathrm{F}\end{array}$} & \multicolumn{5}{|c|}{$p(t)_{\min }, p s i$} \\
\hline & $\begin{array}{c}\Delta t=2.60 \\
a=0\end{array}$ & $\begin{array}{c}\Delta t=2.72 \\
\dot{a}=0\end{array}$ & $\begin{array}{c}\Delta t=2.72 \\
a \neq 0\end{array}$ & $\begin{array}{c}\Delta t=3.00 \\
\dot{a} \neq 0\end{array}$ & $\begin{array}{c}\Delta t=3.12 \\
a \neq 0\end{array}$ \\
\hline 40 & 308 & 307 & 299 & 296 & 295 \\
\hline 45 & & & 334 & & 329 \\
\hline 50 & 382 & 381 & 372 & 369 & 367 \\
\hline 55 & & & 415 & & 409 \\
\hline 60 & 472 & 471 & 462 & 457 & 455 \\
\hline 65 & & & 513 & & 507 \\
\hline 70 & 583 & 581 & 570 & 565 & 563 \\
\hline 75 & & & 631 & & 621 \\
\hline 80 & 705 & 701 & 689 & 681 & 677 \\
\hline 85 & & & 741 & & 727 \\
\hline 88 & 785 & 781 & 768 & 757 & 753 \\
\hline 90 & 804 & 800 & 787 & 776 & 771 \\
\hline 95 & & & 836 & 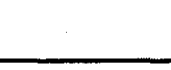 & 820 \\
\hline 100 & 856 & 855 & 841 & 839 & 838 \\
\hline 105 & & & 847 & & 844 \\
\hline 110 & 868 & 868 & 854 & 851 & 850 \\
\hline 115 & & & 861 & & 857 \\
\hline 120 & 883 & 883 & 868 & 866 & 865 \\
\hline
\end{tabular}

a"Optimum" values of $t(H T), e$, and $R T_{N D T_{0}}$ used in the calculations are the same as those in Appendix $B$, with the exception of $T_{v}(t)=95^{\circ} \mathrm{F}$ and $\Delta t=3.12$, for which the optimum values are the same as for $T_{v}(t)=90^{\circ} \mathrm{F}$. 


\subsection{Sensitivity of $p(t)_{\min }$ to flaw growth}

With reference to Eqs. (2) and (3), and considering the upper limit on $\Delta t$ [2.72 EFPY(100 MW)] in Sect. 4.3,

$$
\begin{aligned}
& \Delta a= 8.8 \times 10^{-3} \times 2.72=2.394 \times 10^{-2} \mathrm{in} . \\
&(1+\Delta a / a)^{-0.5}=\left(1+2.394 \times 10^{-2} / 1.0\right)^{-0.5}=0.98824 \\
& \therefore p(t)=(850+326) 0.98824 \frac{K_{l c}(t)}{K_{l c}(H T)}-326 \\
&=1.1622 \times 10^{3} \frac{K_{l c}(t)}{K_{l c}(H T)}-326
\end{aligned}
$$

Corresponding minimum values of $p(t)_{\min }$ are included in Table 3 and Fig. 5 . As indicated, including flaw growth reduces $p(t)_{\min }$ by 8 psi for $T_{v}(t)=40^{\circ} \mathrm{F}$ and by 14 psi for $T_{v}(t)=110^{\circ} \mathrm{F}$, a maximum decrease of only $2 \%$.

Because of the inclusion of $\dot{a} \neq 0$ in Eq. (2), the discontinuity in the curve in Fig. 1 does not occur for $p(t)=p(H T)$, as it did for the two cases for which it was assumed that $a=$ $0[\Delta t=2.60$ and $2.72 \mathrm{EFPY}(100 \mathrm{MW})]$. 
ORNLTM-13355

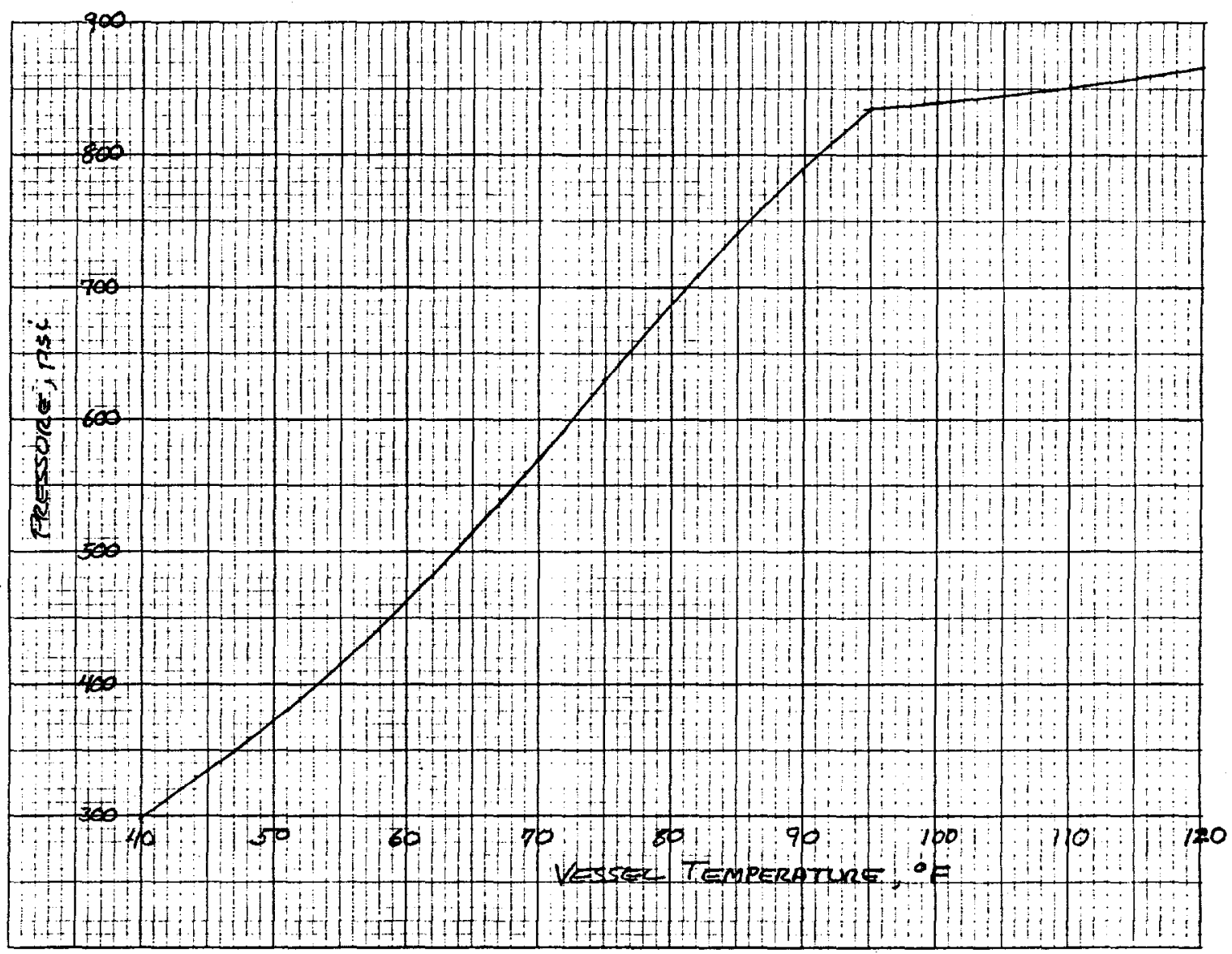

Fig. 5. Maximum permissible pressure [minimum value of $p(t)_{\min }$ ]vs temperature for life extension period 26 to 50 EFPY(100 MW), p(HT) =

$$
\begin{gathered}
850 \mathrm{psi}, \mathrm{T}_{v}(\mathrm{HT})=85^{\circ} \mathrm{F}, \Delta t=2.72 \mathrm{EFPY}(100 \mathrm{MW}), \\
\dot{a}=8.8 \times 10^{-3} \mathrm{in} . / \mathrm{EFPY}(100 \mathrm{MW}) .
\end{gathered}
$$




\subsection{Sensitivity of $p(t)_{\min }$ to characteristics of $K_{/ c}=f\left(T-R T_{N D T}\right)$ curve}

Previous studies have indicated a sensitity of $p(t)_{\min }$ to the characteristics of the $K_{1 c}=$ $f\left(T-R T_{N D T}\right)$ curve. 3,9 It was concluded that for the calculation of $p(H T)$ and $\Delta t$, the ASME lower-bound $K_{l c}$ curve $^{8}$ was appropriate. ${ }^{9}$ Thus, this curve was selected for the present study. As a further check, however, values of $p(t)_{\min }$ were also calculated using the ASME $K_{I R}$ curve, ${ }^{8}$ which is a lower bound to the dynamic and crack arrest data. Results of the comparison analysis (Appendix $F$ ) demonstrate that the ASME lower-bound $K_{i c}$ curve results in the smallest values of $p(t)_{\min }$ and thus is appropriate for this study.

A point of interest with regard to using a lower-bound curve is that the lower-bound curve can be multiplied by a constant to obtain reasonable mean and upper-bound curves that do not alter the values of $p(t)_{\min }$ because, as indicated by Eq. (2), the constant cancels.

\subsection{Minimum value of $p(t)_{\min }$ for $\Delta t=3.0$ and 3.12 EFPY $(100 \mathrm{MW})$ and $a=8.8 \times$ $10^{-3}$ in./EFPY(100 MW)}

It may be that $\Delta t$ will be increased from 2.6 to 3.0 EFPY $(100 \mathrm{MW})$ for the life-extension period 26 to 50 EFPY. Thus, minimum values of $p(t)_{\min }$ were calculated for this nominal value of $\Delta t$ and also for its upper limit [3.12 EFPY(100 MW)], considering flaw growth.

For $\Delta t=3.0$ EFPY $(100 \mathrm{MW})$,

$$
\begin{gathered}
\Delta a=8.8 \times 10^{-3} \times 3.0=0.02640 \mathrm{in} . \\
(1+\Delta a / a)^{-0.5}=(1+0.02640 / 1.0)^{-0.5}=0.98706 \\
\therefore p(t)=1.1608 \times 10^{3} \frac{K_{l c}(t)}{K_{l c}(H T)}-326
\end{gathered}
$$

For $\Delta t=3.12$ EFPY $(100 \mathrm{MW})$, 


$$
\begin{gathered}
\Delta a=8.8 \times 10^{-3} \times 3.12=0.02746 \mathrm{in} . \\
(1+\Delta a / a)^{-0.5}=(1+0.02746 / 1.0)^{-0.5}=0.98655 \\
\therefore p(t)=1.1602 \times 10^{3} \frac{K_{l c}(t)}{K_{l c}(H T)}-326
\end{gathered}
$$

For $\Delta t=3.00$ EFPY $(100 \mathrm{MW})$ and $T_{v}(t)=40-90^{\circ} \mathrm{F}, t=29.00 \mathrm{EFPY}(100 \mathrm{MW})$ and $t(H T)$ $=26.00 ;$ for $\Delta t=3.00$ and $T_{v}(t)=100-120^{\circ} \mathrm{F}, t=50.00$ and $t(H T)=47.00 ;$ for $\Delta t=3.12$ and $T_{v}(t)=40-90^{\circ} \mathrm{F}, t=29.12$ and $t(H T)=26.00 ;$ and for $\Delta t=3.12$ and $T_{v}(t)=100-$ $120^{\circ} \mathrm{F}, t=50.00$ and $t(H T)=46.88$, where $t$ is the time of the minimum value of $p(t)_{\min }$.

The calculated minimum values of $p(t)_{\min }$ are included in Table 3. A comparison of these data with those for $\Delta t=2.60$ and 2.72 EFPY $(100 \mathrm{MW})$ indicates that the reduction in $p(t)_{\min }$ due to increasing $\Delta t$ from 2.6 to $3.0 \mathrm{EFPY}(100 \mathrm{MW})$ is quite small. For $T_{v}(t)=$ $40^{\circ} \mathrm{F}$, the difference in $p(t)_{\min }$ is only 4 psi. At $T_{v}(t)=95^{\circ} \mathrm{F}$ it is $16 \mathrm{psi}$ and at $100^{\circ} \mathrm{F}$ and above it is 4 psi.

In Ref. 8, a value of $\Delta t$ was calculated for the life-extension period 26 to 50 EFPY(100 $\mathrm{MW})$ assuming $p(H T)=850 \mathrm{psi}, T_{v}(H T)=85^{\circ} \mathrm{F}, p(E / \mathrm{F})=679 \mathrm{psi}, T_{v}(E / F)=80^{\circ} \mathrm{F}$, $R T_{\text {NDT }}=-24^{\circ} \mathrm{F}$ (the $-2 \sigma$ value), $t(H T)=26.0$ EFPY $(100 \mathrm{MW}), a(H T)=1.0$ in., and $a$ $=8.8 \times 10^{-3}$ in.$/ E F P Y(100 \mathrm{MW})$. The result was $3.05 \mathrm{EFPY}(100 \mathrm{MW})$. This value was rounded off to 3.00 EFPY $(100 \mathrm{MW})$ for the calculation of $p(t)_{\min }$ in this report, and this explains the difference between $p(E / F)(679 \mathrm{psi})$ and the value of $p(t)_{\min }(681 \mathrm{psi})$ given in Table 3 for $\Delta t=3.0$ EFPY $(100 \mathrm{MW})$ and $T_{v}(t)=80^{\circ} \mathrm{F}$. It is also of interest to note that the value of $p(t)_{\min }$ in Table 3 for $\Delta t=3.12$ EFPY $(100 \mathrm{MW})$ and $T_{\nu}(t)=80^{\circ} \mathrm{F}$ is slightly ( 2 psi) less than $p(E / F)$, as would be expected.

\subsection{Recommendations}

The pressures that should be used as operating limits for HFIR are those calculated using the upper limit on $\Delta t$ and that include flaw growth. The corresponding curve for $\Delta t$ (nominal $)=2.60$ EFPY $(100 \mathrm{MW})$ is presented in Fig. 5 , and the digital data are included in Table 3 for $\Delta t$ (nominal) $=2.60$ and 3.00 EFPY $(100 \mathrm{MW})$. 


\subsection{Summary and Conclusions}

The equal-potential method, which takes advantage of knowledge gained from the hydrostatic proof tests, was used to calculate the maximum permissible pressure as a function of vessel temperature for the proposed vessel life-extension period 26 to 50 EFPY $(100 \mathrm{MW})$. The hydro-test conditions considered were $p(H T)=850 \mathrm{psi}, T_{\mathrm{v}}(H T)=$ $85^{\circ} \mathrm{F}$, and $\Delta t=2.60,2.72,3.00$ and $3.12 \operatorname{EFPY}(100 \mathrm{MW})$, where $\Delta t$ is the time between hydro tests. The four values of $\Delta t$ are (1) the nominal value approved for the period 19.4 to $26.0 \mathrm{EFPY}(100 \mathrm{MW}),(2)$ the corresponding upper-tolerance value, (3) the tentatively proposed nominal value for the period 26 to 50 EFPY(100 MW), and (4) the corresponding upper-tolerance value.

The calculated pressures for $\Delta t=3.12$ EFPY $(100 \mathrm{MW})$ are $295,677,753$, and $850 \mathrm{psi}$ for vessel flaw-tip temperatures of $40,80,88$, and $110^{\circ} \mathrm{F}$. These temperatures are, respectively, the lowest expected, the lowest expected during normal operation, the vessel temperature corresponding to the vessel pressure safety limit, and the vessel temperature for normal operation. Pressures for $\Delta t=2.72$ EFPY $(100 \mathrm{MW})$ are at most only 16 psi higher.

The above pressures are based on the assumption that for each temperature a single value of the maximum permissible pressure is specified for the entire life-extension period. For shorter times, somewhat higher pressures could be specified for vessel temperatures greater than $\sim 95^{\circ} \mathrm{F}$. For temperatures less than $\sim 95^{\circ} \mathrm{F}$, the specified pressure could be increased somewhat with time, but it could never be greater than the hydro-test pressure ( $850 \mathrm{psi}$ ).

As more surveillance data are obtained, it may be possible to decrease the uncertainty factor used for the radiation-induced damage rate, and this would permit some increase in the maximum permissible pressure. 


\section{References}

1. HFIR Technical Specifications, Oak Ridge National Laboratory, ORNL/TM5711/R2, Sect. 3.17.4.

2. ASME Boiler and Pressure Vessel Code, Section III, Division 1, Appendix G, 1992 Edition.

3. R. D. Cheverton and R. K. Nanstad, Evaluation of HFIR Vessel Surveillance Data and Hydro-Test Conditions, Oak Ridge National Laboratory, ORNL/TM12758, August 5, 1994.

4. R. D. Cheverton, J. G. Merkle, and R. K. Nanstad, Evaluation of HFIR PressureVessel Integrity Considering Radiation Embrittlement, Oak Ridge National Laboratory, ORNL/TM-10444, April 1988.

5. R. D. Cheverton, Calculation of HFIR Vessel Pressure/Temperature Limits for Temperatures Below $70^{\circ} \mathrm{F}$, Oak Ridge National Laboratory, Calculation ID: CHFIR-95-009, May 15, 1995.

6. R. D. Cheverton, HFIR Vessel Maximum Permissible Pressure Based on a Vessel Normal Operating Temperature, Oak Ridge National Laboratory, Calculation ID: C-HFIR-95-015, May 15, 1995.

7. R. D. Cheverton, An Evaluation of Life Extension of the HFIR Pressure Vessel, Oak Ridge National Laboratory, ORNL/TM-12877, December 1994.

8. R. D. Cheverton, An Evaluation of Life Extension of the HFIR Pressure Vesse-Supplement 1, Oak Ridge National Laboratory, ORNL/TM-12877/S1, August 1996.

9. ASME Boiler and Pressure Vessel Code, Section XI, Division 1, Appendix A, 1992 Edition. 
10. R. D. Cheverton, Synopsis of Technical Justification for Increasing the Time Between Hydro Tests from 1.0 to 3.0 EFPY(85MW), Letter to J. R. Inger, Oak Ridge National Laboratory, June 2, 1995. 
ORNL/TM-13355

\section{APPENDIX A \\ SOURCE OF STANDARD DEVIATIONS ( $\sigma$ ) FOR $R T_{N D T_{o}}$ and $\Delta R T_{N D T}$}

The reference nil-ductility transition temperature $\left(R T_{N D T}\right)$ is equal to an initial value $\left(\boldsymbol{R} T_{N D T_{o}}\right)$ plus the increase due to radiation exposure $\left(\Delta R T_{N D T}\right)$. That is

$$
R T_{N D T}=R T_{N D T_{0}}+\Delta R T_{N D T}
$$

For nuclear reactor pressure vessel steels, $\Delta R T_{N D T}$ can be obtained from NRC Regulatory Guide 1.99, which has undergone two revisions thus far. ${ }^{A .1,2,3}$ Between the first and second revisions, there was an "improved" version of the correlation that was specified by the NRC for use in the PWR PTS probabilistic fracture-mechanics analysis ${ }^{A .4}$ that was being developed at the time and applied to the PWR IPTS program. A.5 This correlation and its standard deviation $\left(\sigma_{\Delta}\right)$ were proposed by the NRC in an internal document ${ }^{A .6}$ and were eventually included in the Code of Federal Regulations..$^{A .7}$ in Ref. A.6, $\sigma_{\Delta}=24^{\circ} \mathrm{F}$, and, in Ref. A.7, $\sigma_{\Delta}$ is given only in combination with $\sigma_{0}$, the standard deviation for $\boldsymbol{R} T_{N D T_{o}}$. The value of $q$ is given in Ref. A.6 as $17^{\circ} \mathrm{F}$.

In Refs. A.6 and A.7, it is specified that

$$
2 \sigma\left(R N_{N D T}\right)=2 \sqrt{\sigma_{0}^{2}+\sigma_{\Delta}^{2}}
$$

and, consistent with the above values of $\sigma_{0}$ and $\sigma_{\Delta, 2} 2\left(R T_{N D T}\right)=59^{\circ} \mathrm{F}$, which is the combined value given in Ref. A.7 for a generic data base. (No distinction was made between weld, plate, and forging material.) These standard deviations were used in Ref. A.5 and were also used in the HFIR vessel probabilistic fracture-mechanics analyses. ${ }^{A .8}$

For the calculation of the HFIR hydro-test conditions and maximum permissible pressures, $\sigma_{0}= \pm 17^{\circ} \mathrm{F}$ was used, but an uncertainty factor $(e)$ with a range of 0.5 to 1.5 was applied to $\Delta R \dot{T}_{N D T}$, rather than using $\sigma_{\Delta}$ with $\Delta R T_{N D T}$. Within these limits for $e$, there tends to be "optimum" values of $e$ that result in the most restrictive test and operating conditions [maximum value of $p(H T)$, minimum value of $\Delta t$, minimum value of $p(t)_{\min }$ ]. Thus, a search is made for the optimum values of the uncertainties in $\boldsymbol{R} \boldsymbol{T}_{N D T_{o}}$ and $\Delta R T_{N D T}^{\circ}$, using $2 \sigma_{o}= \pm 34^{\circ} \mathrm{F}$ as a limit for $R T_{N D r_{o}}$. 


\section{References (for Appendix A):}

A.1 U. S. Nuclear Regulatory Commission, Effects of Residual Elements on Predicted Radiation Damage to Reactor Pressure Vessel Materials, Regulatory Guide 1.99, July 1975.

A.2 U. S. Nuclear Regulatory Commission, Effects of Residual Elements on Predicted Radiation Damage to Reactor Pressure Vessel Materials, Regulatory Guide 1.99, Rev. 1, Sept. 16, 1976.

A.3 U. S. Nuclear Regulatory Commission, Radiation Embrittlement of Reactor Vessel Materials, Regulatory Guide 1.99, Rev. 2, May 1988.

A.4 R. D. Cheverton and D. G. Ball, OCA-P, A Deterministic and Probabilistic Fracture-Mechanics Code for Application to Pressure Vessels, Oak Ridge National Laboratory, NUREG/CR-3618 (ORNL-5991), May 1984.

A.5 D. L. Selby, et. al., Pressurized Thermal-Shock Evaluation of the HB Robinson Nuclear Power Plant, Oak Ridge National Laboratory, NUREG/CR-4183, Vol. 1 (ORNL/TM-9567N1), September 1985.

A.6 U. S. Nuclear Regulatory Commission, Pressurized Thermal Shock (PTS), SECY-82-465, Attachment A, Letter to USNRC Commissioners, November 23, 1982.

A.7 Code of Federal Regulations, Part 10 CFR 50.61, Fracture Toughness Requirements for Protection Against Pressurized Thermal Shock Events, Revised January 1, 1987.

A.8 R. D. Cheverton and T. L. Dickson, HFIR Vessel Probabilistic FractureMechanics Analysis, Oak Ridge National Laboratory, ORNL/TM-13303, January 1997. 
ORNLTM-13355

\section{APPENDIX B \\ RESULTS OF CALCULATIONS FOR THE PARAMETRIC STUDY}

The purpose of the parametric study was to find which combinations of $t, e$, and $R T_{N D T_{0}}$ resulted in the minimum values of $p(t)_{\min }$. Equations (2)-(8) were used to calculate $p(t)_{\min }$, which corresponds to the time just prior to each hydro test [26+(n-1) 2.6] EFPY $(100 \mathrm{MW})$ and the final time of the life-extension period [50 EFPY(100 MW)]. Minimum values of $p(t)_{\min }$ occur at either $t=28.6$ or 50 EFPY $(100 \mathrm{MW}$ ) (see Appendices $C, D$, and E). Thus, with one exception, $p(t)_{\min }$ was calculated for these two times only. Three values of $e(0.5,1.0,1.5)$ and three values of $R T_{\text {NDT }}\left(-24,10,44^{\circ} \mathrm{F}\right)$ were also considered ( $\pm 2 \sigma$ and mean). The results of the calculations are tabulated below, and the minimum values of $p(t)_{\min }$ are included in Tables 2 and 3 and Fig. 1 of the text and in a summary table at the end of this appendix.

\begin{tabular}{|c|c|c|c|c|c|}
\hline $\begin{array}{c}T_{v}(t) \\
{ }^{\circ} \mathrm{F}\end{array}$ & \multicolumn{2}{|c|}{ EFPY(100 MW) } & $e$ & $R T_{N D T_{o}}$ & $\begin{array}{c}p(t)_{\min } \\
\text { psi }\end{array}$ \\
\hline \multirow[t]{11}{*}{40} & \multirow[t]{11}{*}{28.6} & \multirow[t]{11}{*}{26} & 0.5 & 44 & 538 \\
\hline & & & 0.5 & 10 & 416 \\
\hline & & & 0.5 & -24 & 308 \\
\hline & & & 1.0 & 44 & 635 \\
\hline & & & 1.0 & 10 & 518 \\
\hline & & & 1.0 & -24 & 391 \\
\hline & & & 1.5 & 44 & 714 \\
\hline & & & 1.5 & 10 & 620 \\
\hline & & & 1.5 & -24 & 497 \\
\hline & & & 0.7 & -24 & 337 \\
\hline & & & 1.2 & -24 & 432 \\
\hline \multirow[t]{6}{*}{40} & \multirow[t]{6}{*}{50} & \multirow[t]{6}{*}{47.4} & 0.5 & 44 & 626 \\
\hline & & & 0.5 & 10 & 510 \\
\hline & & & 0.5 & -24 & 388 \\
\hline & & & 1.0 & 44 & 757 \\
\hline & & & 1.0 & 10 & 686 \\
\hline & & & 1.0 & -24 & 583 \\
\hline 50 & 28.6 & 26 & 0.5 & -24 & "382 \\
\hline
\end{tabular}


ORNL/TM-13355

\begin{tabular}{|c|c|c|c|c|c|}
\hline $\begin{array}{l}T_{v}(t) \\
{ }^{\circ} \mathrm{F}\end{array}$ & & $\begin{array}{l}t(H T) \\
M W)\end{array}$ & $e$ & $R T_{N D T_{o}}$ & $\begin{array}{c}p(t)_{\min } \\
\mathrm{psi}\end{array}$ \\
\hline 60 & 28.6 & 26 & $\begin{array}{l}0.5 \\
1.0 \\
1.5 \\
0.75\end{array}$ & $\begin{array}{l}-24 \\
-24 \\
-24 \\
-24\end{array}$ & $\begin{array}{l}472 \\
517 \\
585 \\
491\end{array}$ \\
\hline 70 & 28.6 & 26 & $\begin{array}{l}0.5 \\
1.0 \\
1.5\end{array}$ & $\begin{array}{l}-24 \\
-24 \\
-24\end{array}$ & $\begin{array}{l}583 \\
601 \\
644\end{array}$ \\
\hline 80 & 28.6 & 26 & $\begin{array}{l}0.5 \\
0.5 \\
0.5 \\
1.0 \\
1.0 \\
0.9 \\
1.0 \\
1.1 \\
1.5 \\
1.5 \\
1.5\end{array}$ & $\begin{array}{r}44 \\
10 \\
-24 \\
44 \\
10 \\
-24 \\
-24 \\
-24 \\
44 \\
10 \\
-24\end{array}$ & $\begin{array}{l}774 \\
744 \\
718 \\
782 \\
745 \\
705.3 \\
704.8 \\
705.3 \\
798 \\
763 \\
716\end{array}$ \\
\hline 80 & 50 & 47.4 & $\begin{array}{l}0.5 \\
0.5 \\
0.5 \\
1.0 \\
1.0 \\
1.0 \\
1.5 \\
1.5 \\
1.5\end{array}$ & $\begin{array}{r}44 \\
10 \\
-24 \\
44 \\
10 \\
-24 \\
44 \\
10 \\
-24\end{array}$ & $\begin{array}{l}795 \\
767 \\
737 \\
821 \\
798 \\
766 \\
837 \\
826 \\
807\end{array}$ \\
\hline 85 & 28.6 & 26 & $\begin{array}{l}0.5 \\
1.0 \\
1.5 \\
1.4 \\
1.3\end{array}$ & $\begin{array}{l}-24 \\
-24 \\
-24 \\
-24 \\
-24\end{array}$ & $\begin{array}{l}796 \\
765 \\
758 \\
\cdot 758 \\
758\end{array}$ \\
\hline 88 & 28.6 & 26 & 1.5 & -24 & "785 \\
\hline
\end{tabular}


ORNL/TM-13355

\begin{tabular}{|c|c|c|c|c|c|}
\hline $\begin{array}{l}T_{v}(t) \\
{ }^{\circ} \mathrm{F}\end{array}$ & \multicolumn{2}{|c|}{ EFPY $(100 \mathrm{MW})$} & $e$ & $R T_{N D T_{o}}$ & $\begin{array}{c}p(t)_{\min } \\
p s i\end{array}$ \\
\hline \multirow[t]{9}{*}{90} & \multirow[t]{9}{*}{28.6} & \multirow[t]{9}{*}{26} & 0.5 & 44 & 869 \\
\hline & & & 0.5 & 10 & 876 \\
\hline & & & 0.5 & -24 & 883 \\
\hline & & & 1.0 & 44 & 841 \\
\hline & & & 1.0 & 10 & 836 \\
\hline & & & 1.0 & -24 & 831 \\
\hline & & & 1.5 & 44 & 832 \\
\hline & & & 1.5 & 10 & 820 \\
\hline & & & 1.5 & -24 & "804 \\
\hline \multirow[t]{9}{*}{90} & \multirow[t]{9}{*}{50} & \multirow[t]{9}{*}{47.4} & 0.5 & 44 & 864 \\
\hline & & & 0.5 & 10 & 871 \\
\hline & & & 0.5 & -24 & 878 \\
\hline & & & 1.0 & 44 & 846 \\
\hline & & & 1.0 & 10 & 843 \\
\hline & & & 1.0 & -24 & 839 \\
\hline & & & 1.5 & 44 & 846 \\
\hline & & & 1.5 & 10 & 842 \\
\hline & & & 1.5 & -24 & 835 \\
\hline \multirow[t]{9}{*}{95} & \multirow[t]{3}{*}{28.6} & \multirow[t]{3}{*}{26} & 1.5 & 44 & 852 \\
\hline & & & 1.5 & 10 & 853 \\
\hline & & & 1.5 & -24 & 855 \\
\hline & \multirow[t]{3}{*}{39} & \multirow[t]{3}{*}{36.4} & 1.5 & 44 & 851 \\
\hline & & & 1.5 & 10 & 852 \\
\hline & & & 1.5 & -24 & 853 \\
\hline & \multirow[t]{3}{*}{50} & \multirow[t]{3}{*}{47.4} & 1.5 & 44 & 850 \\
\hline & & & 1.5 & 10 & 851 \\
\hline & & & 1.5 & -24 & 852 \\
\hline
\end{tabular}


ORNL/TM-13355

\begin{tabular}{|c|c|c|c|c|c|}
\hline $\begin{array}{c}T_{v}(t) \\
{ }^{\circ} \mathrm{F}\end{array}$ & \multicolumn{2}{|c|}{$\begin{array}{l}t \quad t(H T) \\
\text { EFPY }(100 \mathrm{MW})\end{array}$} & $e$ & $R T_{N D T_{0}}$ & $\begin{array}{l}p(t)_{\min } \\
p s i\end{array}$ \\
\hline \multirow[t]{9}{*}{100} & \multirow[t]{9}{*}{28.6} & \multirow[t]{9}{*}{26} & 0.5 & 44 & 985 \\
\hline & & & 0.5 & 10 & 1037 \\
\hline & & & 0.5 & -24 & 1084 \\
\hline & & & 1.0 & 44 & 913 \\
\hline & & & 1.0 & 10 & 948 \\
\hline & & & 1.0 & -24 & 985 \\
\hline & & & 1.5 & 44 & 874 \\
\hline & & & 1.5 & 10 & 890 \\
\hline & & & 1.5 & -24 & 912 \\
\hline \multirow[t]{9}{*}{100} & \multirow[t]{9}{*}{50} & \multirow[t]{9}{*}{47.4} & 0.5 & 44 & 947 \\
\hline & & & 0.5 & 10 & 997 \\
\hline & & & 0.5 & -24 & 1049 \\
\hline & & & 1.0 & 44 & 877 \\
\hline & & & 1.0 & 10 & 898 \\
\hline & & & 1.0 & -24 & 929 \\
\hline & & & 1.5 & 44 & "856 \\
\hline & & & 1.5 & 10 & 861 \\
\hline & & & 1.5 & -24 & 870 \\
\hline \multirow[t]{9}{*}{110} & \multirow[t]{9}{*}{28.6} & \multirow[t]{9}{*}{26} & 0.5 & 44 & 1126 \\
\hline & & & 0.5 & 10 & 1235 \\
\hline & & & 0.5 & -24 & 1330 \\
\hline & & & 1.0 & 44 & 1002 \\
\hline & & & 1.0 & 10 & 1084 \\
\hline & & & 1.0 & -24 & 1174 \\
\hline & & & 1.5 & 44 & 924 \\
\hline & & & 1.5 & 10 & 976 \\
\hline & & & 1.5 & -24 & 1043 \\
\hline
\end{tabular}


ORNL/TM-13355

\begin{tabular}{|c|c|c|c|c|c|}
\hline $\begin{array}{c}T_{v}(t) \\
{ }^{\circ} \mathrm{F}\end{array}$ & \multicolumn{2}{|c|}{ EFPY(100 MW) } & $e$ & $R T_{N D T_{0}}$ & $\begin{array}{c}p(t)_{\min } \\
\text { psi }\end{array}$ \\
\hline \multirow[t]{9}{*}{110} & 50 & 47.4 & 0.5 & 44 & 1049 \\
\hline & & & 0.5 & 10 & 1151 \\
\hline & & & 0.5 & -24 & 1259 \\
\hline & & & 1.0 & 44 & 915 \\
\hline & & & 1.0 & 10 & 965 \\
\hline & & & 1.0 & -24 & 1038 \\
\hline & & & 1.5 & 44 & "868 \\
\hline & & & 1.5 & 10 & 884 \\
\hline & & & 1.5 & -24 & 913 \\
\hline 120 & 50 & 47.4 & 1.5 & 44 & 883" \\
\hline
\end{tabular}

*Minimum values of $p(t)_{\min }$. 
ORNL/TM-13355

Summary of minimum values of $p(t)_{\min }$

\begin{tabular}{c|c|c|c|c|c}
\hline$T_{v}(t)$ & $t$ & $t(H T)$ & $e$ & $R T_{N D T_{0}}$ & $p(t)_{\min }$ \\
\hline 40 & 28.6 & 26 & 0.5 & -24 & 308 \\
\hline 50 & 28.6 & 26 & 0.5 & -24 & 382 \\
\hline 60 & 28.6 & 26 & 0.5 & -24 & 472 \\
\hline 70 & 28.6 & 26 & 0.5 & -24 & 583 \\
\hline 80 & 28.6 & 26 & 1.0 & -24 & 705 \\
\hline 85 & 28.6 & 26 & 1.4 & -24 & 758 \\
\hline 88 & 28.6 & 26 & 1.5 & -24 & 785 \\
\hline 90 & 28.6 & 26 & 1.5 & -24 & 804 \\
\hline 95 & 50 & 47.4 & 1.5 & 44 & 850 \\
\hline 100 & 50 & 47.4 & 1.5 & 44 & 856 \\
\hline 110 & 50 & 47.4 & 1.5 & 44 & 868 \\
\hline 120 & 50 & 47.4 & 1.5 & 44 & 883 \\
\hline
\end{tabular}




\section{APPENDIX C \\ CALCULATED VALUES OF $p(t)$ vs $t$ FOR $T_{v}(t)=110^{\circ} \mathrm{F}$, $\Delta t=2.6 \operatorname{EFPY}(100 \mathrm{MW}), \dot{\mathrm{a}}=0$}

Equations $(2)-(8)$ were used to calculate the time dependence of $p(t)$ for values of $e$ and $R T_{N D T}$ 。 that result in the minimum value of $p(t)_{\min }$ (see Appendix $B$ ). Calculations were made for $\Delta t=2.6 \mathrm{EFPY}(100 \mathrm{MW})$ considering and also not considering the beneficial effect of hydro testing. The latter calculation was performed assuming a hydro test at 26 EFPY(100 MW) only. Results are presented below in Table C.1 and also in Fig. 2 of the text.

Table C.1. Calculated values of $p(t)$ vs $t$, with and without the beneficial effects of hydro testing, for $T_{v}(t)=110^{\circ} \mathrm{F}, p(H T)=850 \mathrm{psi}, T_{v}(H T)=85^{\circ} \mathrm{F}, \Delta t=2.6$ EFPY $(100$ $M W), t(H T)$ (initial) $=26$ EFPY $(100 \mathrm{MW}), e=1.5, R T_{N D T_{0}}=44^{\circ} \mathrm{F}, a=0$

\begin{tabular}{|c|c|c|c|}
\hline $\begin{array}{c}t \\
\operatorname{EFPY}(100 \mathrm{MW})\end{array}$ & $\begin{array}{c}t(H T) \\
\text { EFPY }(100 \mathrm{MW})\end{array}$ & $\begin{array}{c}T_{v}(t)-R T_{N D T} \\
{ }^{\circ} \mathrm{F}\end{array}$ & $\begin{array}{l}p(t) \\
\text { psi }\end{array}$ \\
\hline 26 & 26 & -29 & 983 \\
\hline 28.6 & 26 & -39 & 924 \\
\hline 28.6 & 28.6 & -39 & 963 \\
\hline 31.2 & 26 & -48 & 876 \\
\hline 31.2 & 28.6 & -48 & 913 \\
\hline 31.2 & 31.2 & -48 & 946 \\
\hline 33.8 & 26 & -58 & 836 \\
\hline 33.8 & 31.2 & -58 & 904 \\
\hline 33.8 & 33.8 & -58 & 931 \\
\hline 47.4 & 26 & -107 & 715 \\
\hline 47.4 & 44.8 & -107 & 872 \\
\hline 47.4 & 47.4 & -107 & 882 \\
\hline 50 & 26 & -117 & 703 \\
\hline 50 & 47.4 & -117 & 868 \\
\hline 50 & 50 & -117 & 877 \\
\hline
\end{tabular}




\section{APPENDIX D}

CALCULATED VALUES OF $p(t)$ vs $t$ FOR $T_{v}(t)=88^{\circ} \mathrm{F}$,

$$
\Delta t=2.6 \mathrm{EFPY}(100 \mathrm{MW}), a \dot{a}=0
$$

Equations (2)-(8) were used to calculate the time dependence of $p(t)$ for values of $e$ and $R T_{N D T_{0}}$ that result in the minimum value of $p(t)_{\min }$ (see Appendix $B$ ). Calculations were made for $\Delta t=2.6 \mathrm{EFPY}(100 \mathrm{MW})$ considering and also not considering the beneficial effect of hydro testing. The latter calculation was performed assuming a hydro test at 26 EFPY(100 MW) only. Results are presented below in Table D. 1 and also in Fig. 3 of the text.

Table D.1. Calculated values of $p(t)$ vs $t$, with and without the beneficial effects of hydro testing, for $T_{v}(t)=88^{\circ} \mathrm{F}, p(H T)=850 \mathrm{psi}, T_{v}(H T)=85^{\circ} \mathrm{F}, \Delta t=2.6 \mathrm{EFPY}$

\begin{tabular}{c|c|c|c}
\hline \multicolumn{5}{c|}{$t$} & $\begin{array}{c}t(H T) \\
\text { EFPY(100 MW) }\end{array}$ & $\begin{array}{c}T_{v}(t)-R T_{N D T} \\
{ }^{\circ} \mathrm{F}\end{array}$ & $\begin{array}{c}p(t) \\
p s i\end{array}$ \\
\hline 26 & 26 & 17 & 883 \\
\hline 28.6 & 26 & 7 & 785 \\
\hline 28.6 & 28.6 & 7 & 879 \\
\hline 31.2 & 26 & -2 & 704 \\
\hline 31.2 & 28.6 & -2 & 792 \\
\hline 31.2 & 31.2 & -2 & 876 \\
\hline 33.8 & 26 & -12 & 638 \\
\hline 33.8 & 31.2 & -12 & 798 \\
\hline 33.8 & 33.8 & -12 & 873 \\
\hline 47.4 & 26 & -61 & 437 \\
\hline 47.4 & 44.8 & -61 & 825 \\
\hline 47.4 & 47.4 & -61 & 861 \\
\hline 50 & 26 & -71 & 416 \\
\hline 50 & 47.4 & -71 & 829 \\
\hline 50 & 50 & -71 & 859 \\
\hline
\end{tabular}




\section{APPENDIX E \\ CALCULATED VALUES OF $p(t)$ vs $t$ FOR $T_{v}(t)=80^{\circ} \mathrm{F}$, $\Delta t=2.6 \operatorname{EFPY}(100 \mathrm{MW}), \dot{\mathrm{a}}=0$}

Equations (2)-(8) were used to calculate the time dependence of $p(t)$ for values of $e$ and $R T_{N D T}$ 。 that result in the minimum value of $p(t)_{\min }$ (see Appendix $B$ ). Calculations were made for $\Delta t=2.6 \mathrm{EFPY}(100 \mathrm{MW})$ considering and also not considering the beneficial effect of hydro testing. The latter calculation was performed assuming a hydro test at 26 EFPY(100 MW) only. Results are presented below in Table E. 1 and also in Fig. 4 of the text.

Table E.1. Calculated values of $p(t)$ vs $t$, with and without the beneficial effects of hydro testing, for $T_{v}(t)=80^{\circ} \mathrm{F}, p(H T)=850 \mathrm{psi}, T_{v}(H T)=85^{\circ} \mathrm{F}, \Delta t=$ 2.6 EFPY $(100 \mathrm{MW}), e=0.5$ and $1.0, R T_{N D T_{0}}=-24^{\circ} \mathrm{F}, \dot{\mathrm{a}}=0$

\begin{tabular}{c|c|c|c|c}
\hline \multirow{2}{*}{$t$} & $t(H T)$ & $T_{v}(t)-R T_{N D T}$ & \multicolumn{2}{|c}{$p(t), p s i$} \\
\cline { 4 - 5 } EFPY $(100 \mathrm{MW})$ & EFPY(100 MW) & ${ }^{\circ} \mathrm{F}$ & $e=1.0$ & $e=0.5$ \\
\hline 26 & 26 & 41 & 782 & \\
\hline 28.6 & 26 & & 705 & \\
\hline 28.6 & 28.6 & & 637 & \\
\hline 31.2 & 26 & 28 & 712 & 720 \\
\hline 31.2 & 28.6 & & 789 & \\
\hline 31.2 & 31.2 & & 577 & \\
\hline 33.8 & 26 & 22 & 720 & 722 \\
\hline 33.8 & 31.2 & & 792 & \\
\hline 33.8 & 33.8 & & 362 & \\
\hline 47.4 & 26 & & 759 & 735 \\
\hline 47.4 & 44.8 & & 810 & \\
\hline 47.4 & 47.4 & & 335 & \\
\hline 50 & 26 & & 766 & 737 \\
\hline 50 & 47.4 & & 814 & \\
\hline 50 & 50 & & &
\end{tabular}




\section{APPENDIX F \\ COMPARISON OF $p(t)$ vs e OBTAINED USING THE \\ ASME $K_{i c}$ AND $K_{I R}$ CURVES}

In Ref. 4, the ASME $K_{I R}$ vs $T-R T_{\text {NDT }}$ curve $^{2}$ was used in the calculation of the hydro-test conditions. More recently, ${ }^{3,8}$ it was recognized that other "reasonable" curves might result in somewhat more stringent conditions, and eventually the ASME $K_{l c}$ curve was selected as the most reasonable. As indicated in Tables F1, 2, and 3, use of the $K_{k}$ curve results in lower values of $p(t)_{\min }$ than obtained using the $K_{\mathbb{R}}$ curve. The two fracture-toughness curves used in the comparison calculations are as follows:

$$
\begin{aligned}
& K_{l c}=33.2+20.73 \exp \left[0.02\left(T-R T_{N D T}\right)\right], \\
& K_{I R}=26.8+12.44 \exp \left[0.0145\left(T-R T_{N D T}\right)\right]
\end{aligned}
$$

As discussed in the text, the values of $p(t)_{\min }$ of concern are those that correspond to 0.5 $\leq e \leq 1.5$, where $e$ is the uncertainty factor applied to $\triangle N D^{\circ} T T$. These values of $p(t)_{\min }$ are also given in Appendix $B$, and the corresponding times and temperatures listed in Appendix B are the ones that were used in this appendix for the comparison calculations.

\begin{tabular}{|c|c|c|}
\hline \multirow[t]{2}{*}{$e$} & \multicolumn{2}{|c|}{$p(t), p s i$} \\
\hline & $K_{1 c}$ curve & $K_{I R}$ curve \\
\hline 0.50 & 308 & 503 \\
\hline 0.75 & 345 & 529 \\
\hline 1.00 & 391 & 558 \\
\hline 1.25 & 442 & 588 \\
\hline 1.50 & 497 & 617 \\
\hline 1.75 & 553 & 647 \\
\hline 2.00 & 605 & 674 \\
\hline
\end{tabular}

Table F1. Values of $p(t)$ vs e obtained using the ASME $K_{1 c}$ and $K_{I R}$ curves, $T_{v}(t)=$ 
Table F2. Values of $p(t)$ vs e obtained using the ASME $K_{I c}$ and $K_{I R}$ curves, $T_{v}(t)=88^{\circ} \mathrm{F}, t=28.6 \mathrm{EFPY}(100 \mathrm{MW}), t(\mathrm{HT})=26.0 \mathrm{EFPY}(100 \mathrm{MW})$,

\begin{tabular}{|c|c|c|}
\hline & $=-24^{\circ} \mathrm{F}$, & \\
\hline \multirow[t]{2}{*}{$e$} & \multicolumn{2}{|c|}{$p(t), \mathrm{psi}$} \\
\hline & $K_{1 c}$ curve & $K_{\text {IR }}$ curve \\
\hline 0.50 & 847 & 848 \\
\hline 0.75 & 822 & 834 \\
\hline 1.00 & 804 & 824 \\
\hline 1.25 & 791 & 816 \\
\hline 1.50 & 785 & 812 \\
\hline 1.75 & 784 & 809 \\
\hline 2.00 & 787 & 809 \\
\hline
\end{tabular}

Table F3. Values of $p(t)$ vs e obtained using the ASME $K_{1 c}$ and $K_{1 R}$ curves, $T_{v}(t)=$

\begin{tabular}{|c|c|c|}
\hline \multirow[t]{2}{*}{$e$} & \multicolumn{2}{|c|}{$p(t), p s i$} \\
\hline & $K_{l c}$ curve & $K_{1 R}$ curve \\
\hline 0.50 & 1049 & 967 \\
\hline 0.75 & 967 & 927 \\
\hline 1.00 & 915 & 900 \\
\hline 1.25 & 885 & 881 \\
\hline 1.50 & 868 & 869 \\
\hline 1.75 & 859 & 861 \\
\hline 2.00 & 854 & 857 \\
\hline
\end{tabular}




\section{INTERNAL DISTRIBUTION}

1. W. K. Brown

2. S. E. Burnette

3. S. J. Chang

4-8. R. D. Cheverton

9. D. H. Cook

10. R. E. Daniels (DOE-ORO)

11. H. R. Fair (DOE-ORO)

12. M. B. Farrar

13. G. F. Flanagan

14. M. L. Gildner

15. R. E. Hale

16. R. W. Hobbs

17-27. J. R. Inger

28. M. W. Kohring

29. J. E. Lee
30. M. A. Linn

31. R. S. McKeehan

32. J. G. Merkle

33. L. D. Merryman

34. R. K. Nanstad

35. L. D. Proctor

36. R. B. Rothrock

37. R. M. Stinnett

38. E. L. Watkins III

39. T. Yahr

40. RRD-DCC

41. Central Research Library

42. Document Reference Section

43-44. Laboratory Records

45. Laboratory Records (RC)

\section{EXTERNAL DISTRIBUTION}

46. E. G. Tourigny, Office of Nuclear Energy, NE-40-GTN, Department of Energy, Germantown, MD, 20874-1290.

47. E. G. Cumsesty, ORNL Site Manager, Department of Energy-ORO, Oak Ridge, TN, 37831-6269.

48-49. Office of Scientific and Technical Information, Post Office Box 62, Oak Ridge, TN, 37831. 